\title{
Inclusion Body Measurement
}

National Cancer Institute

\section{Source}

National Cancer Institute. Inclusion Body Measurement. NCI Thesaurus. Code C116184.

A measurement of the protein, lipid or small molecule aggreg ates located within the cytoplasm. 